\title{
Vectors of Musical Tastes Reconfiguration in Consumer Society
}

\author{
Vladimir Kozlovskiy \\ The Sociological institute of the Russian Academy of \\ Science \\ Saint Petersburg State University \\ St. Petersburg, Russia \\ vvk_soc@mail.ru
}

\author{
Daria Tkachuk \\ Saint Petersburg State University \\ St. Petersburg, Russia \\ tkachuk.daria@gmail.com
}

\begin{abstract}
This paper deals with issue of reconfiguration of musical tastes in consumer society. Nowadays music production is one of the most developed sectors in cultural industry. Various musical forms are often considered to be clearly reflective markers of social inequality, cultural identity and selectiveness in cultural consumption. Listeners can easily operate within a list of contrasting alternatives of musical pieces on all possible levels (e.g. genres, associated with highbrow, middlebrow and lowbrow culture). The article presents the results of the analysis of global social and non-social vectors, as well as social institutions which impact on process of cultural taste modifications. Musical tastes are expressing dichotomy of being both modifiers of cultural consumption on individual and group level and consequence of it.
\end{abstract}

Keywords-Consumer society; Forms of music production; Patterns of music consumption; Musical tastes; Cultural commodification; Reconfiguration of musical tastes

\section{INTRODUCTION}

Modern music production is considered to be fast growing sector in cultural industry: in 2017 the global recorded music market grew by $8.1 \%$, and global recorded music revenues totalled $\$ 17.3$ billion [1]. However, music is highly influential not only economically, but culturally: music consumption is a type of aesthetic experience, which could impact both positively and negatively on groups and individuals. Nevertheless, the patterns of musical creativity, as well as demonstrated listening patterns implied in different social groups are one of examples of cultural selectiveness. The beginning of the inclusion into the "sounding" space is related to the very first moments of human existence: for instance, in number of recent studies were measured the abilities of yet unborn humans to decode various music pieces and even react in different way to the music of an exact genre [2]. In the current paper we focus on an issue of selectiveness towards consumption of musical forms and practices of listening. Expressed interest to music consumption, for instance, is related to global economic development and directly correlate with current socio-economical situation. The central issue is the reconfiguration of listener's system of musical tastes under the influence of various social and non-social vectors, as well as social institutions: the accepted and rejected pieces of music, genres, musical practices. Our assessments are based on the hypothesis that the essence of musical communications is

The reported study was funded by RFBR according to the research project № 16-06-00572. aimed to external "broadcast" and modification of selfreflected dynamic taste system.

\section{MusicAl taste IN Social ScIENCES}

In the middle of the twentieth century music and musical practices became one of the central objects of sociological research. For example, in "Sociology of Music" Theodor Adorno presumes the existence of correlations between musical preferences and the socio-demographic characteristics of listeners; he creates one of the first sociological classifications of listeners [3]. In 1970-1980s musical tastes were one of the issues in Pierre Bourdieu studies: vast empirical data became the basis for his interpretative status based model of musical and cultural tastes as types of the manifestation of habitus. He described legitimate, middlebrow and popular taste in context of distinctions, based on genres, styles, authors etc. Bourdieu describes pieces of art and music as complex hierarchically organized code systems, which lead both to recreation and reproduction of social inequality. So that, demonstrated aesthetic taste, as well as the practices of interaction with art and high culture, primarily is the "evidence of belonging to the desired social category" [4]. A number of Bourdieu's works, in which he presented the results of his studies, became highly influential on sociomusicologists: some concepts were reinterpreted in order to reflect global and local cultural realities. For instance, Bourdieu's conceptualization became the basis of $\mathrm{O}$. Lizardo studies [5].

The second modern approach to the study of musical tastes was developed in the 1990s by a group of researchers, primarily Richard A. Peterson and Roger M. Kern. This approach is also highly oriented towards inequality and status issues, however, unlike the Bourdieu's model, it is based on expressed dichotomy between omnivores and univores (snobs). One of the key points is that representatives of highbrow culture demonstrate more omnivoreness in patterns of aesthetic (music) consumption then non-highbrows. What is more, modern highbrows like more kinds of non-elite music in various genres then highbrows in 1980s and earlier [6]. Of course, the idea that mass culture in post-industrial communication is an indispensable basis for various network connections appears earlier in cultural and sociological studies [5], for example, in the work of DiMaggio "Classification of 
Art" [7]. In the context of cultural consumption, musical tastes are primarily considered to be a result of aesthetic experience generated by various cultural industries. It is important to take into account the duality of culture that manifests itself in consumer practices. Mainly, the practices of a music listener include the consumption of objectified, supra-individual cultural products that form a peculiar basis of its socio-cultural experience, and subjected, individually interpreted and generated cultural products. In modern consumer society these two types of cultural forms are developing the new types of music related products and practices.

TABLE I. DIVERSITY IN MUSIC PRODUCTS PRODUCTION AND BROADCAST

\begin{tabular}{|l|l|l|}
\hline Level 1 & Level 2 & Level 3 \\
\hline Sheet music, musical score & Intabulation and other types of instrumental and vocal arrangements \\
\hline Records (both digital and physical) & $\begin{array}{l}\text { Remixes, Covers, composer's and original } \\
\text { performance interpretations, remashed versions }\end{array}$ & $\begin{array}{l}\text { Second-order interpretations (e.g. interpretation of } \\
\text { covers and remixes) }\end{array}$ \\
\hline $\begin{array}{l}\text { Media broadcasts of live concerts or musical } \\
\text { records (videos), streaming }\end{array}$ & Recording of broadcasts, their interpretations \\
\hline $\begin{array}{l}\text { Live performances (concerts, festivals) } \\
\text { Live music theatre and musicals }\end{array}$ & $\begin{array}{l}\text { Professional video or audio recording of live } \\
\text { performances }\end{array}$ & $\begin{array}{l}\text { Records of live performance, made by listeners } \\
\text { (individualized artifacts) }\end{array}$ \\
\hline Music video & $\begin{array}{l}\text { Professional video or audio recording of live } \\
\text { perfonces }\end{array}$ & $\begin{array}{l}\text { Second-order interpretations such as films based on } \\
\text { musicals/performances }\end{array}$ \\
\hline
\end{tabular}

We observe three main levels of musical products and practices. In addition to live performances and records, the forms of first include original music videos, music scores. The second level consists of first-order interpretation. They can be done by the original performers themselves (for example, through release of records of new versions of tracks), professional musicians or other artists (for example, parodies of musical clips), amateurs (e.g. cover versions of songs). The third level, which we presume as the result of cultural commodification, consists of interpretations of interpretations, or second-order interpretations.

\section{VECTORS OF MUSICAL TASTES RECONFIGURATION AND MODIFICATION IN CONSUMER SOCIETY}

In sociological studies of cultural tastes, including musical tastes, some factors indirectly correlate with social selectiveness of consumption patterns should be considered. Since we regard musical tastes as modifying system generated by aesthetic experience which remains in a state of constant reconfiguration under the external and internal influence the main vectors of modification should be defined.

Psychological. The consumption of music is both personal and collective experience: it is associated with intimate practices and at the same time it is arising from the sharing of similar experiences and values with other listeners [8]. There is a suggestion that music is more concerned with emotions than other forms of art, and less complex musical forms evoke strong emotional responses from listeners. Psychological vector of the reconfiguration of musical taste is related to the experience of emotional expression and, but one should understand that musical experience is a complex way of cultural consumption. Music is used by individuals, for example, as a tool which structures time and space (in particular, it often becomes a reason for background listening to music in transport or while processing work activities) [9]. In addition, at the intersection of sociology and social psychology researchers also discuss issues of the relation between music and self or self-identity. Thus, selectiveness towards certain genres or specific compositions can in fact indicate not only individual's social position, but also his life experience, biographical self-reflection or a number of individually defined values.

Technological. The growth of musical availability is directly related to the development of recording and broadcasting technologies. The limited access to the various musical forms makes the whole musical field repressive towards the listener. In such conditions the development of cultural omnivoreness becomes difficult. Sometimes the obstacles are generated under the influence of political vector, but in most modern consumer societies, mainly western, technologies are considerably more influential on normal activities of musical industries than government restrictions. Molteni and Ordanini [10] singled out three key changes in cultural consumption in the context of technological development: quality uncertainty, demand reversal, social contagion process. Musical content quality definitely becomes one of the key issues in curren music related discussins. On one hand, we follow the critical attitude of D. Hesmondhalgh towards uncritical populism, which accepts for the quality standards those proposed by the music industry. 
Hesmondhalgh explains that initiatives in the framework of such populism with regard to cultural equality are reduced to "renouncement of exclusivity and snobbery of high culture in relation to low" [11]. On the other hand, the consumption of cultural products in general is difficult to be qualitatively measured [10]. There are no objective criteria that make it possible to conclude unambiguously that composition or genre is "low" or "high" quality. In many studies, related to the consumption practices, preferences and tastes are considered to express not individual but group patterns of cultural consumption, habitus of this group or strata. With technological development music became more accessible (both economically and "physically") to the potential consumers: digital music is relatively cheap or even free. The primary selectiveness of musical products has changed as the listening practices have changed themselves. To start with, we suppose that focused album listening becomes rarer and is possibly related to those music performances that can be marked as core for the listener.

Digital technologies have reduced the cost of copying and transmitting information [12], but, in return, they also are thought to be the main reason of increased illegal music listening practices. However, in the empirical study of internet activity of music listeners (both legal and illegal) researcher found no evidence of a negative effect of unlicensed music downloading on digital music purchasing. On the other hand, they consider that listeners' behavior depends on his or her cultural and social background: the research has shown a number of country-unique characteristics that affect digital consumptions, including copyright-specific laws and market forces. What is more, Aguiar and Martens assume that music loves consuming preferences include more different channels and ways of doing it [12].

Economical. In the context of the economic vector of the reconfiguration of tastes, we should firstly mention the industrial production of music and musical tastes. Cultural Industries can be defined as organizations "mediating flows of cultural goods between producers and consumers, reconciling the demands of art production with those of the marketplace" [8]. For music industries, musical taste is the main indicator of the safest direction to work in. Therefore, contrary to the external diversity of music products, it is more cost-effective to standardize its production and distribution (at least on as many stages as it is possible). In addition, if we talk about the feasibility of producing cultural products, in our opinion, we can assume a systematic "imposition" of certain tastes for music. What is more, music industries nowadays are more concentrated on selected songs and hit production and marketing, then on album releases. Hit making is definitely not new tendency in music industry: it is economically effective to produce a hit that will amortize the investments to the other commercial music products. However, until the beginning of XXI century the main sources of personalized music replications were physical carriers, such as CDs, cassettes and others. Thus, by buying an album or song collection, the listener demonstrated more thoughtful patterns of listening. In modern conditions when access to music is almost unlimited, and, therefore, listeners' is not focused on everyday listening itself, it is unlikely that he or she will listen to a song that does not hook in the first few seconds. As a result, the whole cognitive logic of musical perception changes.

Physiological and cognitive. There are a number of crossdiscipline explanations of musical origins. While sociologists relate music genesis mainly with its role in various rituals, there are some evidences that music is a co-product of human language [13]. Music itself cannot be defined as a specific linguistic form; however, development of linguistic abilities during human evolution is connected with development of language and acoustic senses, related to reaction to the complex sound environment. The biological vector is in close connection with the psychological. For example, in the functional plan for the human body, music is able to change the stress reactions of the skin and the circulation of stress hormones; moreover, it affects various cerebral activities [2]. Accordingly, musicality is associated not only with positive emotions and conscious emotional regulation, but also with intense negative emotions: aggression, cruelty [2]. The other area of studies, related to neurological explanations of musical influence on human is related to music-evoked memories; for instance, P. Janata in 2007 developed a paradigm for characterizing autobiographical memories where he considered that experience of such memories "does indeed activate portions of the MPFC as well as a broader network implicated in previous studies of autobiographical memory retrieval" [14]. Music can also be an instrument of cognition, as well as the part of his complex process. Psychological and interdisciplinary works show controversial results in researches of associations between music and cognitive abilities. There is various empirical evidence of the link between music aptitude and selective cognitive abilities, such as reading, linguistic abilities, phonological processing, but no empirical prove of strong correlations between others, such as music aptitude and mathematical abilities (e.g. the estimated overall level of musicality among mathematicians with doctoral degree is not higher than the level of musicality, demonstrated by equally qualified humanities scholars) [15].

Political. Music industry main function is not just development of new cultural forms, but economical efficacy. We suppose there are three key political forms of interaction with music industry: stimulation, restriction and neutrality. Political vector transforms taste mainly via the first two. Governmental support of some cultural forms is observed in relation of those cultural are considered as acceptable or useful for current cultural policy; what is more, there ais a number of historical examples of support of concrete genre in order to transform national identities [11]. Contrary, there is a restriction and creation of artificial obstacles to those music and cultural forms that are thought to cause destruction of governmentally approved cultural systems. As a result, musical industry in its taste reconfiguration and recreation have to react not only to the pure economical global stream, but reflect on geopolitical transformations.

Axiological. Axiological vector of musical taste formation is related to the symbolic level of music itself, as well as with the expressed values and axiological basis of social groups who consume the concrete music. Subcultures and postsubcultures accumulate and transmit their manifested values 
through various media, and music could be one of them. However, modern musical genres are becoming more and more convergent, which leads to fragmental expressions of values throughout concrete genres. S. Firth believes that in music are rather articulated not beliefs of the social group, but understanding of group relations and individuality; on their bases ethical codes and social ideologies are created [16].

Cultural. The musical tastes of listeners as consumers of musical pieces constitute the core of musical culture. Accordingly, they directly or indirectly form, lead and reconfigurate the musical consumption, which is provided by the music and cultural industry, the music business. Obviously, the structure, content and richness of musical preferences are formed in the process of cultural socialization, education, social communication, under the influence of media etc. The cultural vector of the reconfiguration of musical tastes in the consumer society is creating and maintaining the conditions for the cultural production of musical compositions, the infrastructure for reproduction and popularization of musical things.

Social. We consider that the social vector is reproduced in two dimensions. The first is conversation of symbolical boundaries generated by musical taste patterns into hierarchical boundaries. The second is related to social distance, which is connected to the exclusion and inclusion dynamics. One of the bases for our hypnosis is Bryson's model where he describes how «individuals use cultural taste to reinforce symbolic boundaries between themselves and categories of people they dislike» [17].

\section{CONCLUSION}

Various musical forms are often considered to be clearly reflective markers of social inequality, cultural identity and selectiveness in cultural consumption. Listeners can easily operate within a list of contrasting alternatives of musical pieces on all possible levels (e.g. genres, associated with highbrow, middlebrow and lowbrow culture). The article presents the results of the analysis of global social and nonsocial vectors, as well as social institutions which impact on process of cultural taste modifications. Musical tastes are expressing dichotomy of being both modifiers of cultural consumption on individual and group level and consequence of it. In the conditions of wide musical diversity, which, among other things, has been strengthened due to the simplification of the technology of production of a musical products, fierce competition between performers of a same musical genre or musical direction, the creators of music (composers, artists, authors of lyrics, etc.) faced with necessity to produce compositions that would not be rejected while unfocused or background hearing.

\section{REFERENCES}

[1] Global Music Report 2017: Annual State of the Industry http://www.ifpi.org/downloads/GMR2017.pdf.

[2] C. Trevarthen. Human biochronology: on the source and functions of 'musicality'. In: Haas R., Brandes V. (eds) Music that works. Springer, Vienna, 2009.

[3] T. Adorno. Introduction to the sociology of music. The Seabury Press, New York, 1976

[4] P. Bourdieu. Distinction: A Social Critique of the Judgement of Taste. Harvard University Press, 1984, 613 p.

[5] O.Lizardo. How Cultural Tastes Sjhape Personal American Sociological Review 71(5), 2006, pp. 778-807.

[6] R. Peterson, R., \& R. Kern. Changing Highbrow Taste: From Snob to Omnivore. American Sociological Review, 61(5), 1996, pp. 900-907.

[7] P. DiMagio. Classification of Art, American Sociological Review, 52(4), 1987, pp. 440-455.

[8] D. Hesmondhalgh D. Towards a critical understanding of music, emotion and self-identity, Consumption Markets \& Culture, 11:4, 2008, pp.329-343.

[9] B. Diemert. Time and Timelessness: Contexts for Popular Music in Resounding Pasts: Essays in Momcilovic D (eds) Literature, Popular Music and Cultural Memory Cambridge Scholars Publishing, 2011.

[10] L. Molteni, A. Ordanini. Consumption Patterns, Digital Technology and Music Downloading. Long Range Planning - LONG RANGE PLANN. 36, 2003, pp. 389-406.

[11] D. Hesmondhalgh. Why Music Matters? Wiley-Blackwell, 2016.

[12] L. Aguiar, B. Martens. Digital music consumption on the internet: evidence from clickstream data in Information Economics and Policy 34, 2016, pp. 27-43.

[13] J. G. Roederer. Music and the evolution of human brain function in: Haas R., Brandes V. (eds) Music that works. Springer, Vienna, 2009.

[14] P. Janat. Music and self in In: Haas R., Brandes V. (eds) Music that works. Springer, Vienna, 2009.

[15] G. Schellenberg, M. W. Weiss. Music and Cognitive Abilities in Diana Deutsch (eds) Psychology of Music Music, Elsevier Inc., 2013, pp.499550.

[16] S. Frith. Music and Identities in Hall S., Gay P. (eds) Questions of Cultural Identity, London: Sage, 1996. pp. 108-127.

[17] B. Bryson. "Anything But Heavy Metal": Symbolic Exclusion and Musical Dislikes. American Sociological Review, 61(5), 1996, pp. 884899. 